\title{
Excitatory Synaptic Drive for Swimming Mediated by Amino Acid Receptors in the Lamprey
}

\author{
N. Dale \\ Department of Physiology III, Karolinska Institute, S113 44 Stockholm, Sweden
}

In order to investigate the properties and pharmacology of the excitatory synaptic drive received by motoneurons during swimming in the lamprey, propriospinal excitatory interneurons were activated as a population by the regional application of $N$-methyl-D,L-aspartate (NMA) to either the 6-8 rostral-most or the 68 caudal-most segments of lengths of isolated spinal cord. This caused a rhythmic motor output to be generated in these regions. Synaptic potentials that were phase-locked to, and dependent on, the rhythmic motor activity of the segments exposed to the agonist could be recorded in motoneurons lying outside the activated regions.

The synaptic drive to motoneurons located rostral or caudal to the activated regions was studied. Motoneurons received both descending and ascending synaptic input, which consisted of alternating excitatory and inhibitory phases. The inhibition could be reversed by chloride injection and blocked by strychnine, leaving an oscillating excitatory phase. The descending excitatory drive could extend 1-9 segments from the active region, while the ascending excitatory drive was recorded only in motoneurons that were 1-3 segments rostral to the active region. Both types of drive occurred in phase with the ipsilateral ventral root discharge: The peak depolarization of the descending drive occurred at the same point in the swimming cycle as that of the depolarizing phase seen during fictive swimming, while that of the ascending drive occurred significantly later. Both ascending and descending drives were partially reduced in amplitude by 2-amino-5-phosphonovaleric acid or $\mathrm{Mg}^{2+}$. The blocking action of $\mathrm{Mg}^{2+}$ was, in both cases, voltage dependent. Cis-2,3-piperidine dicarboxylic acid or kynurenic acid caused a much greater reduction in the amplitude of the oscillations.

These results suggest that a major part of the excitatory drive for swimming in lamprey motoneurons is generated by populations of propriospinal interneurons with relatively long descending and/or short ascending axons, which fire rhythmically during swimming and release an amino acid transmitter that excites motoneurons through $\boldsymbol{N}$-methyl-D-aspartate (NMDA) and nonNMDA receptors. This information will allow these important neurons to be identified in future experiments.

Rhythmic movements and locomotion in both vertebrates and invertebrates are believed to be controlled by networks of neurons capable of producing a motor output largely appropriate to control that behavior in the absence of sensory feedback (see

\footnotetext{
Received Jan. 7, 1986; revised Mar. 14, 1986; accepted Mar. 17, 1986.

I wish to thank Prof. S. Grillner, Drs. J. Buchanan, R. Hill, and P. Wallén for helpful advice during the course of this work and for valuable criticism of this manuscript, $H$. Axegren for excellent technical assistance and help with the illustrations, and the S.E.R.C. for financial support and the Swedish Medical Research Council.(Project No. 3026).

Correspondence should be addressed to Dr. N. Dale, Center for Neurobiology and Behavior, Columbia University, 722 West 168th Street, New York, NY 10032.

Copyright $(\mathcal{C} 1986$ Society for Neuroscience $0270-6474 / 86 / 092662-14 \$ 02.00 / 0$
}

Delcomyn, 1980, for review). Much progress has been made in understanding the operation of these networks, called central pattern generators, in invertebrates (for reviews, see Roberts and Roberts, 1983). In all vertebrates so far examined, the locomotor central pattern generator generates alternating periods of excitation and inhibition in motoneurons during each movement cycle (e.g., Kahn, 1982; Perret, 1983; Russell and Wallén, 1983; Soffe and Roberts, 1982). While some understanding of the mechanisms underlying the generation of the phasic inhibition has been achieved (e.g., Buchanan, 1982; Dale, 1985; Feldman and Orlovsky, 1975; Rovainen, 1974), there is almost total ignorance of the mechanisms underlying the generation of excitation and the excitatory interneurons that presumably belong to these networks and play a crucial role in their function. Only in the Xenopus embryo has it been possible, so far, to characterize physiologically the excitatory premotor interneurons that play an important role in the generation of the swimming motor pattern (Dale and Roberts, 1985). This paper attempts to describe the excitatory drive received by lamprey motoneurons and some inhibitory premotor interneurons during swimming. Only by knowing in detail the properties of the excitation received by motoneurons during swimming will it be possible to identify the neurons and mechanisms that underlie its generation.

Excitatory amino acid transmitters, often assumed to be glutamate and/or aspartate, can act at 3 sorts of receptor, named $N$-methyl-D-aspartate (NMDA), kainate, and quisqualate receptors after their most potent and selective agonists (Watkins and Evans, 1981). Isolated segments of lamprey spinal cord can be made to swim by the addition of exogenous amino acid agonists that act at NMDA and/or kainate receptors (Brodin et al., 1985a), suggesting that swimming is activated by a transmitter acting at these receptors (Brodin and Grillner, 1985). Furthermore, motoneurons receive 2 types of excitatory PSP mediated by a transmitter acting at amino acid receptors: a slow NMDA receptor-mediated EPSP and a fast kainate/quisqualate receptor-mediated EPSP (Dale and Grillner, 1986). These EPSPs arc almost identical in shape, time course, and pharmacology to those previously shown in the Xenopus embryo to be important in the generation of the excitatory drive for motoneurons during swimming in this preparation (Dale and Roberts, 1985). It is therefore reasonable to ask whether the excitatory drive for motoneurons in the lamprey is also mediated by NMDA and kainate/quisqualate receptors.

In order to investigate this problem, a preparation of lamprey spinal cord some 10-20 segments long was devised in which the central pattern generator for swimming was activated in only the rostral-most 6-8 segments. If excitatory interneurons were present in these rostral segments, and had long descending axons, they might be expected to synapse onto motoneurons in more caudal segments. Excitatory potentials in caudal motoneurons would therefore reflect the activity of excitatory interneurons activated by the central pattern generator in the rostral 
segments. The strategy was therefore to examine the properties and pharmacology of EPSPs in caudal motoneurons that were phase-locked to, and dependent on, the activity (as monitored by ventral root recordings) in the rostral part. Similar experiments were also performed in which the caudal-most 6-8 segments were exposed to $N$-methyl-D, L-aspartate (NMA) in order to look for ascending excitatory drive.

The results presented here show that motoneurons receive an oscillating excitatory input in phase with the ipsilateral ventral root discharge of the active rostral or caudal segments. This excitation is mediated by an endogenous transmitter acting at NMDA and kainate/quisqualate receptors that may well be released by interneurons firing rhythmically in phase with the motoneurons they excite.

\section{Materials and Methods}

All experiments were performed on specimens of Ichthyomyzon uni cuspis that were between 10 and $20 \mathrm{~cm}$ long. The lampreys were anesthetized with MS 222, and the spinal cord-notochord was dissected out. This was kept in oxygenated saline, and experiments were done either on the isolated spinal cord (Wallén et al., 1985) or with preparations in which the spinal cord remained attached to the notochord, the bottom half of which had been removed to improve visibility. In this latter case, the preparation was carefully pinned out, and if any movements were observed when the exogenous amino acid agonist was added, tubocurarine chloride ( $15 \mathrm{mg} /$ liter) was added to the bathing medium. The intracellular recording electrode was also placed on the surface of the spinal cord to check for any movement artifacts.

\section{The partitioned preparation}

Lengths of spinal cord 10-20 segments long were prepared for recording in a saline containing $91 \mathrm{~mm} \mathrm{NaCl}, 2.1 \mathrm{mM} \mathrm{KCl}, 20 \mathrm{~mm} \mathrm{NaHCO}_{3}, 2.6$ $\mathrm{mM} \mathrm{CaCl}, 1.8 \mathrm{mM} \mathrm{MgCl}_{2}$, and $4 \mathrm{~mm}$ glucose that was bubbled with $95 \% \mathrm{O}_{2} / 5 \% \mathrm{CO}_{2}$. Once this had been done, either the 6-8 most rostral segments (for a "rostrally driven" preparation) or the 6-8 most caudal segments (for a "caudally driven" preparation) were isolated from the rest of the bath. In order to do this, a ring about $20 \mathrm{~mm}$ in diameter and $5 \mathrm{~mm}$ high was fashioned from acetate sheet, and a carefully tailored notch cut in one edge so that the ring would fit closely over the spinal cord but not crush it. A tight seal was made by first coating the bottom edge of the ring with petroleum jelly, then draining the bath of saline and soaking up any remaining fluid near the preparation with tissue. The ring was then placed over the spinal cord and pressed gently down. The bath and circular pool were then refilled with saline-the pool to a higher level than the bath. The pool was carefully checked for leaks, and any that did occur were made good by squirting petroleum jelly into the offending holes. The complete seal was no wider than 1 segment. Throughout an experiment, the level of saline in the pool was maintained a few millimeters higher than that of the rest of the bath, so that any slow leakage that might occur would be outward rather than inward. The level of fluid in the pool remained fairly constant over periods of at least an hour. If any outward leakage did occur, it must therefore have been very slow. Assuming the worst possible case, if the pool emptied during $1 \mathrm{hr}$ (something that never happened), the rate of leakage would be about $25 \mu \mathrm{l} / \mathrm{min}-100$ times slower than the rate of superfusion of the bath $(2.5 \mathrm{ml} / \mathrm{min})$. It was important that antagonists could not leak into the pool, since the plan was to evoke swimming by agonist application within the pool and look at the effect of antagonists on EPSPs recorded outside the pool. If antagonists were to leak into the pool they might weaken the swimming rhythm and thereby weaken the EPSPs recorded outside the pool without having any direct effect on the EPSPs themselves. This did not occur because (1) the level of the fluid within the pool was always higher than that outside, (2) application of antagonists reduced the amplitude of EPSPs outside the pool but had no noticeable effect on the burst intensity or frequency of swimming within the pool, and (3) when $\mathrm{Mg}^{2+}$ was added back to the medium outside the pool, it reduced the amplitude of EPSPs recorded outside the pool. This cannot possibly be explained by leakage of $\mathbf{M g}^{2+}$ into the pool and weakening swimming since $\mathrm{Mg}^{2+}$ was present inside the pool at the same concentration throughout the whole of an experiment.

Once the seal around the pool had been established, the rest of the bath was continually superfused with fresh saline containing $5 \mathrm{~mm} \mathrm{Ca} \mathrm{Ca}^{2+}$ but no $\mathrm{Mg}^{2+}(2.5 \mathrm{ml} / \mathrm{min})$. Fictive swimming was then evoked in the segments enclosed by the pool by adding 50-200 $\mu \mathrm{M}$ NMA to the bathing medium. Swimming could be monitored by making ventral root recordings in the pool (Figs. 1, 10). Ventral root recordings were also made from the "silent" part lying outside the pool.

Lengths of spinal cord were used from just caudal to the gill region to just rostral to the anus. No differences were seen between lengths of spinal cord taken from different parts of the animal. Therefore, the use of "rostral" and "caudal" in the text refers not to the position of the spinal cord segments relative to the whole animal but only to the rostral and caudal ends of an isolated length of spinal cord.

\section{Electrophysiological recordings}

Conventional equipment was used to make intra- and extracellular recordings, the data being stored on a 7 channel tape recorder (Racal) for later analysis. During the initial experiments, electrodes filled with $5 \%$ Lucifer yellow in $0.3 \mathrm{M} \mathrm{LiCl}$ and bevelled to a resistance of $100-200$ $M \Omega$ were used to effect an anatomical identification of the recorded neurons. In subsequent experiments, electrodes filled with $3 \mathrm{~m} \mathrm{KCl}$ or $3 \mathrm{M}$ potassium acetate $(40-100 \mathrm{M} \Omega$ ) were used and motoneurons were identified physiologically by recording $1: 1$ spikes in the adjacent ventral root during suprathreshold intracellular stimulation of the motoneuron. These results are based on recordings from 106 neurons in 29 preparations, 54 of which were physiologically or anatomically identified motoneurons.

\section{Measurements}

The peak amplitude of oscillations received by motoneurons during an ipsilateral ventral root burst was measured relative to the membrane potential just preceding the ventral root burst. Between 10 and 30 consecutive oscillations were measured to give a mean amplitude.

The phase relation of the depolarizing phase of the oscillation to the ipsilateral ventral root discharge occurring in the driven segments $(\phi)$ was measured using the method of Buchanan and Cohen (1982). The time of the onset of the ipsilateral ventral root burst to the moment of peak depolarization was expressed as a fraction of the total cycle period. Five measurements were made from 8 identified motoneurons (giving a total of $n=40$ ) for both the ascending and descending oscillations. All measurements were made from oscillations occurring in salines containing $5 \times 10^{-6} \mathrm{M}$ strychnine and no $\mathrm{Mg}^{2+}$, and from motoneurons that were between 4 and 6 segments away from the ipsilateral ventral root.

Statistical comparisons were made, if required, using Student's $t$ test.

\section{Pharmacological agents}

2-Amino-5-phosphonovaleric acid (APV) and cis-2,3-piperidine dicarboxylic acid (PDA) were obtained from Cambridge Research Biochemicals, while NMA and kynurenic acid (KYAC) came from Sigma. Strychnine nitrate was obtained from the local pharmacy.

\section{Results}

\section{Rostrally driven partitioned preparations}

In preparations in which the rostral 6-8 spinal cord segments were exposed to NMA (Fig. $1 A$ ), and in consequence generated an alternating motor output, the membrane potential of motoneurons in the caudal "inactive" part oscillated in phase with the rostral ventral root discharge (Fig. $1 B$ ). In addition, a low level of rhythmic activity could be recorded from ventral roots up to 4 segments caudal to the partition. These membrane potential oscillations consisted of alternating inhibitory and excitatory phases. The rhythmic inhibition (observed in the absence of strychnine) occurred in phase with the contralateral ventral root discharge; it could be reversed by hyperpolarizing current and/or chloride injection (Fig. 1C) and blocked by the addition of $5 \times 10^{-6} \mathrm{M}$ strychnine (Fig. 1C). This left an excitatory input that was clearly rhythmic and occurred in phase with the ipsilateral ventral root discharge $(\phi=0.20, \mathrm{SD}=0.11$, $n=40$ ). This phase value is very similar to that obtained for the oscillations occurring in myotomal motoneurons during fictive swimming evoked by the bath application of excitatory amino acid agonists (Buchanan and Cohen, 1982). 
A

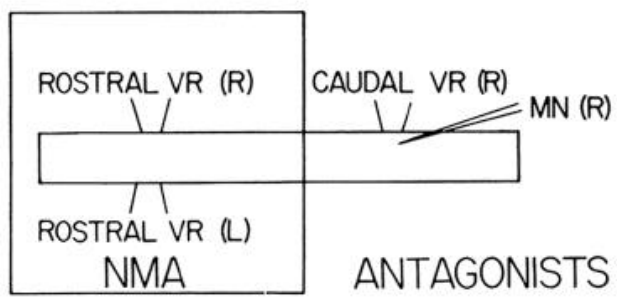

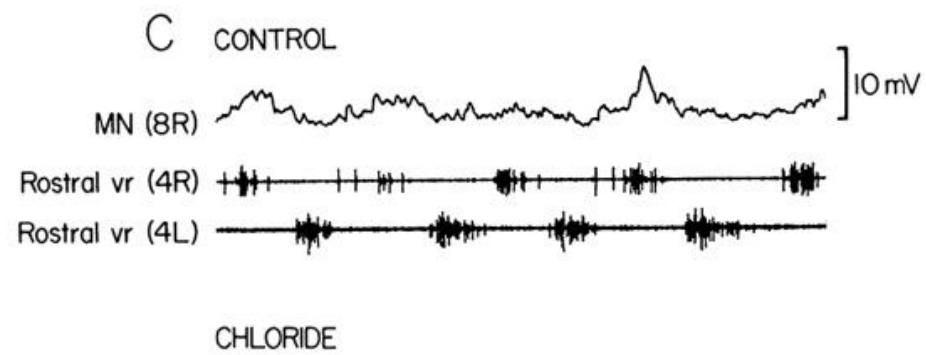

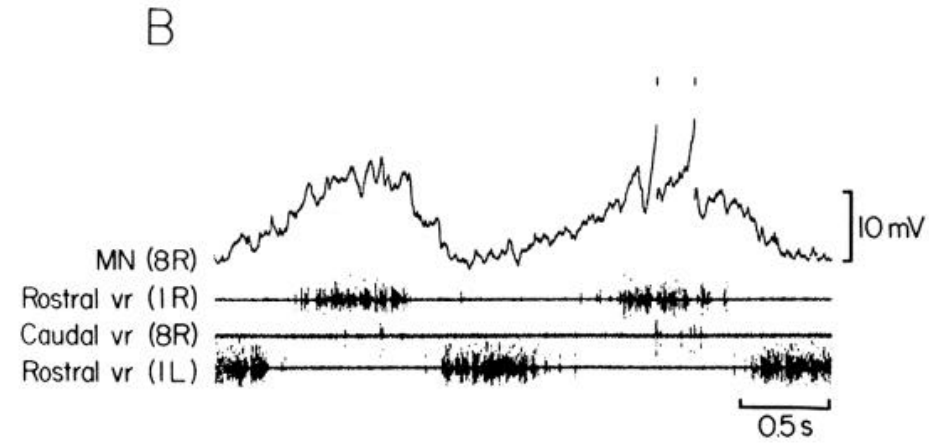

Figure 1. The rostrally driven partitioned preparation. A, The rostral part of the spinal cord was enclosed in a separate sealed pool and exposed to NMA in order to evoke swimming. The caudal part was continually superfused with control saline and could be exposed to antagonists. Swimming activity was monitored by making ventral root recordings from the left and right sides of the spinal cord $[V R(L)$ and $V R(R)]$, while recordings from motoneurons $[M N(R)]$ could be made in the caudal part. $B$, Descending synaptic drive recorded in a motoneuron 1 segment caudal to a partition in a $\mathrm{Mg}^{2+}$-free saline containing $5 \mathrm{~mm} \mathrm{Ca}^{2+}$. The electrode placements and names correspond to those of $A$. $C$, Inhibitory phase of the descending drive could be reversed by chloride injection and subsequently blocked by $5 \times 10^{-6} \mathrm{M}$ strychnine. This experiment was performed in a $20 \mathrm{mM} \mathrm{Ca}^{2+}$ saline, and the motoneuron was recorded 1 segment caudal to the partition. In all 3 traces, the motoneuron is shown at resting potential.

A

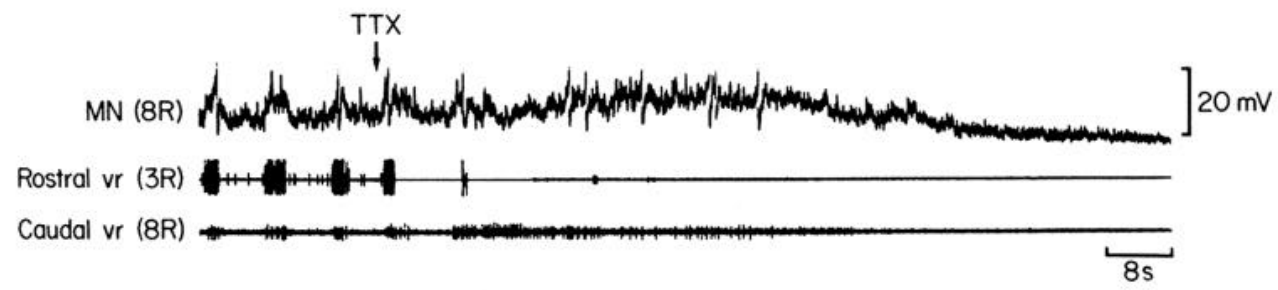

B
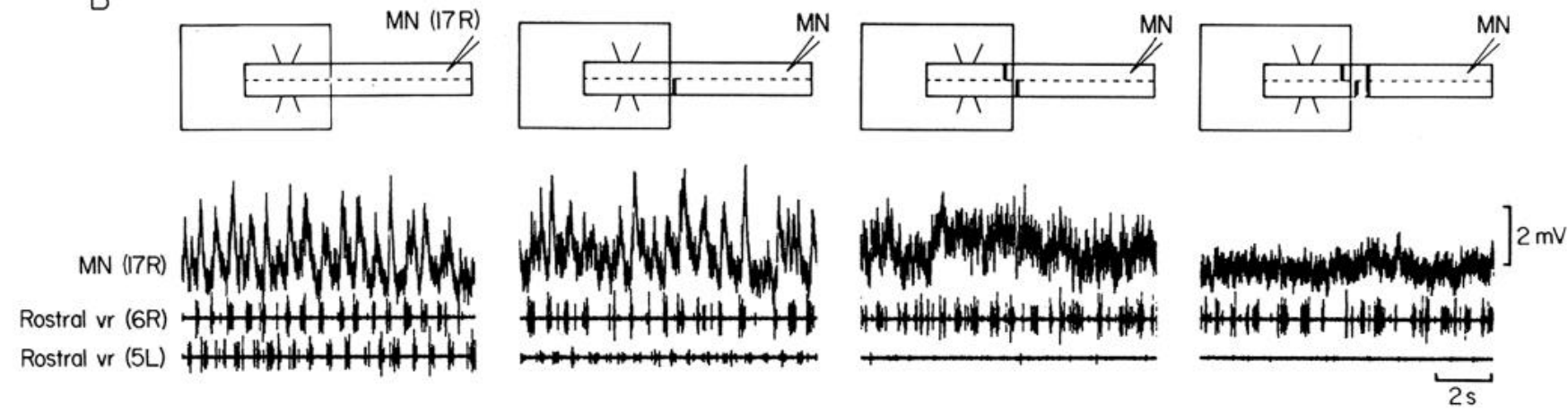

Figure 2. Dependence of the descending excitatory drive on the activity in the rostrally driven pool. $A$, Effect of changing the fluid of the rostral pool from a saline containing $100 \mu \mathrm{M}$ NMA to one containing $100 \mu \mathrm{M}$ NMA $/ 3 \times 10^{-6} \mathrm{M}$ TTX. The caudal motoneuron could still fire spikes to intracellular current injection $5 \mathrm{~min}$ after the TTX had had its effect in the rostral pool (not shown). $B$, Effect of lesions (illustrated above the corresponding traces) on the descending excitatory drive. The partition was at segment 7-8. In this and all subsequent figures, unless otherwise stated, the motoneurons were recorded in $\mathrm{Mg}^{2+}$-free salines containing $5 \times 10^{-6} \mathrm{M}$ strychnine. 
$A$

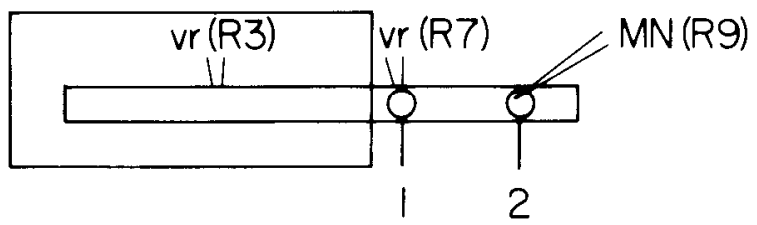

B GLYCINE (I)

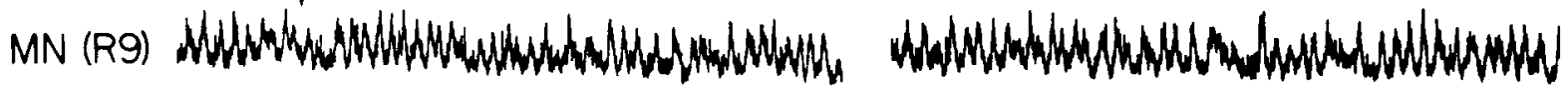
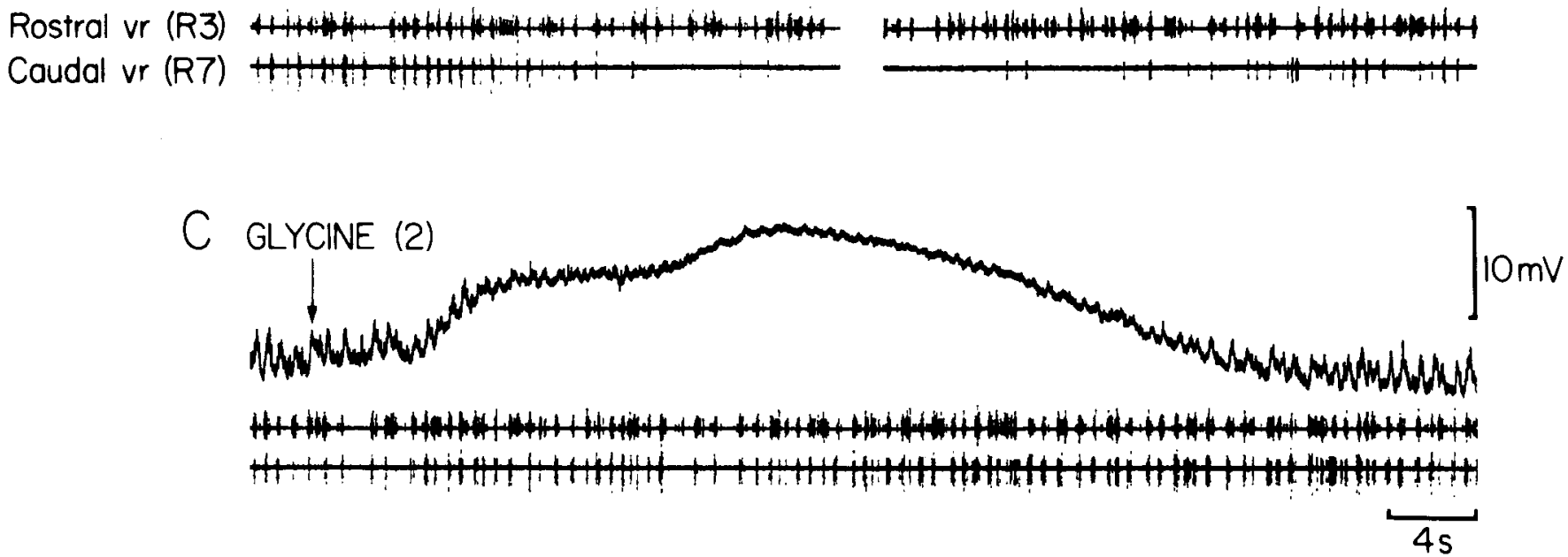

Figure 3. Effect of droplets of $50 \mathrm{~mm}$ glycine applied either proximal or distal to a motoneuron recorded in salines lacking strychnine and $\mathrm{Mg}^{2+}$. $A$, Diagram showing the placement of the electrodes and locations of droplet administration. $B$, Effect of glycine applied to position 1 . There is a break of $36 \mathrm{sec}$ in this trace. $C$, Effect of a second glycine droplet applied to position 2 immediately after recovery from effects of the first application of glycine.

\section{Dependence of synaptic drive on neurons in the rostral segments} These oscillations in caudal motoneurons were dependent on the activity in the rostral compartment. If $10^{-6} \mathrm{M}$ TTX was added to the rostral pool $(n=4)$, rhythmic activity in the rostral ventral roots ceased almost immediately and was replaced by a few seconds of tonic discharge and then silence. The oscillations in the caudal motoneuron disappeared in parallel with these effects, replaced first by a brief depolarization, and then by a complete cessation of synaptic activity, even though the motoneuron itself could still fire spikes to intracellular current injection (Fig. $2 A)$. Transections of the spinal cord $(n=4)$ either just rostral or just caudal to the partition (Fig. $2 B$ ) also confirmed that the oscillations in neurons 2-9 segments caudal to the partition were dependent on activity descending from the rostral "swimming" portion. Contralateral hemisections had little effect on the oscillations, while ipsilateral hemisections either on their own or in conjunction with contralateral hemisections (Fig. $2 B$ ) abolished the oscillations. Complete transections also abolished the oscillations (Fig. $2 B$ ).

The excitatory synaptic input to motoneurons in these preparations may possibly be monosynaptic. The amplitude of the oscillations was unaffected by the elevation of $\mathrm{Ca}^{2+}$ in the saline from its normal value of 5 to $20 \mathrm{~mm}(n=5)$. This treatment raises the threshold of neurons and has been previously used as a test for monosynaptic transmission (see Berry and Pentreath, 1976, for review). In these preparations the addition of strychnine to the saline bathing the caudal part of the spinal cord could result in large spontaneous EPSPs and bursts in the caudal ventral root that were obviously unrelated to the swimming rhythm of the rostral portion. Elevation of the $\mathrm{Ca}^{2+}$ levels to 20 mM completely abolished this strychnine-induced spontaneous activity, providing independent evidence that this treatment was effective in blocking at least some polysynaptic transmission.

One further type of experiment $(n=6)$ was performed to test whether these oscillations could be monosynaptic. In order to cause a strong inhibition of interneurons within circumscribed areas of the spinal cord, small droplets of $50 \mathrm{~mm}$ glycine ( $c f$. Rovainen, 1985) were applied either very close to motoneurons recorded 3 segments caudal to the partition, or to the first segment caudal to the partition (Fig. $3 A$ ). If the excitation was transmitted along the spinal cord to motoneurons by a polysynaptic pathway, application of glycine droplets just caudal to the partition would be expected to reduce the excitation in more caudal motoneurons by depressing the activity of interposed interneurons. When a glycine droplet was applied close to the motoneuron, it depolarized the cell (presumably due to the elevation of the chloride equilibrium potential due to the use of $\mathrm{KCl}$ electrodes) and caused an almost complete abolition of the oscillations (Fig. 3C). However, when the same or larger droplet 


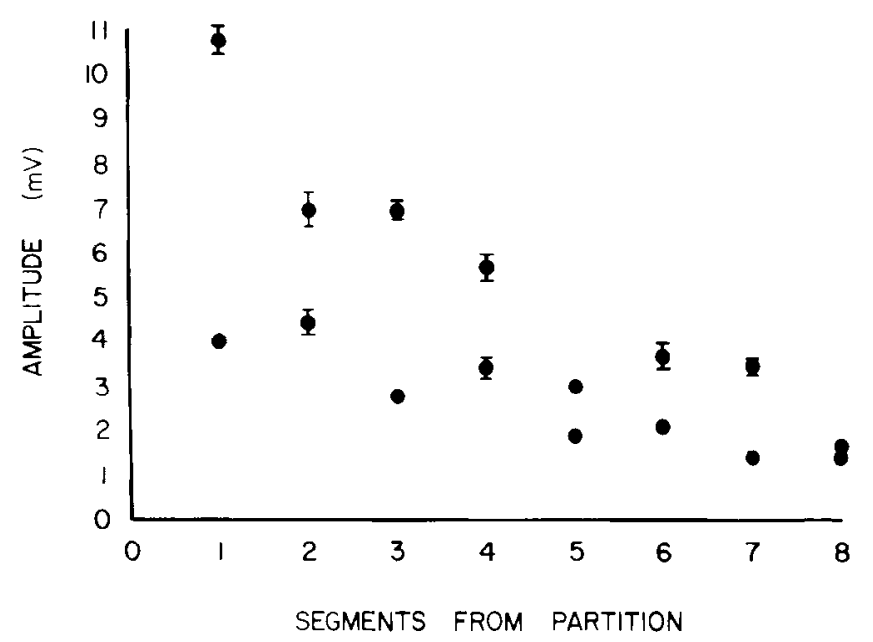

Figure 4. Amplitude of the descending drive decreases with distance from the partition recorded in salines lacking strychnine and $\mathrm{Mg}^{2+}$. A series of 16 spinal cord neurons recorded in a preparation at successively greater distances from the partition. Each had a resting potential of at least $-55 \mathrm{mV}$ and a spike that overshot zero by at least $20 \mathrm{mV}$. Each point is a mean of 10 measurements and SEM bars are shown only where these are greater than the size of the dot.

of glycine was applied to the segment just caudal to the partition, there was little or no effect on the amplitude of oscillations (Fig. $3 B$ ), even though the ventral root activity of that segment was abolished (Fig. 3B). This suggests that neurons in the caudal part of the spinal cord, even those close to the partition, did not contribute to the synaptic drive received by more caudal motoneurons. The possibility that interposed nonspiking interneurons located close to the motoneuron somata might contribute to the synaptic drive cannot be excluded.

Taken together, these results indicate that a substantial part of the oscillations is monosynaptic and probably arises from the actions of interneurons lying in the rostral "active" portion, which fire rhythmically and have relatively long descending axons. The amplitude of oscillations seemed to depend on how close the recorded motoneuron was to the active portion of the spinal cord. An experiment was performed in which neurons were impaled at successively greater distances from the partition (Fig. 4). Close to the partition the oscillations were as large as $11 \mathrm{mV}$ in amplitude; with greater distances the amplitude of the oscillations gradually declined, reaching about $1.5 \mathrm{mV}$ at 8 segments from the partition (Fig. 4). The oscillations recorded in cells more distant from the partition seemed to be more obviously composed of recognizable component EPSPs (Fig. 5). Since unitary EPSPs evoked in motoneurons can have an amplitude of 0.5-2 mV (Dale and Grillner, 1986), oscillations of $1-2 \mathrm{mV}$ may be generated by the actions of only a very few interneurons.

\section{Pharmacology of the descending excitatory drive}

All pharmacological manipulations were done in salines containing $5 \times 10^{-6} \mathrm{M}$ strychnine, so the effect of antagonists on the excitation could be examined without the presence of any inhibition that might obscure their effects.

\section{$N M D A$ receptor antagonists}

When $100 \mu \mathrm{M}$ APV, a specific NMDA antagonist (Brodin and Grillner, 1985; Dale and Grillner, 1986; Dale and Roberts, 1984; Davies et al., 1981; Wallén and Grillner, 1985), was applied to the bathing medium surrounding the caudal spinal cord, it reversibly abolished rhythmic ventral root activity in the caudal part but did not affect or weaken ongoing ventral root activity
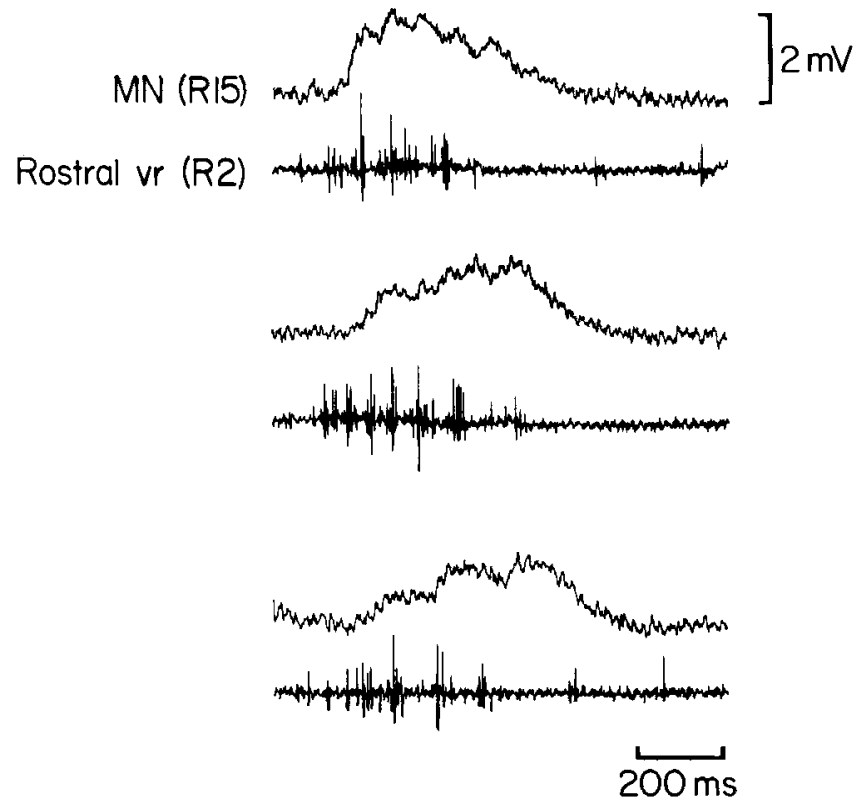

Figure 5. Excitatory potentials recorded in a neuron 8 segments caudal to the partition. The oscillations seem to be composed of component EPSPs.

in the rostral spinal cord (Fig. 6). It also caused a reversible reduction in the amplitude of oscillations recorded in motoneurons $1-4$ segments caudal to the partition (mean, 29\%; range, 16-50\%; SEM, 4.0; $n=8$; see Fig. 6).

The addition of $1.8 \mathrm{mM} \mathrm{Mg}{ }^{2+}$, also a specific NMDA antagonist (Ault et al., 1980; Dale and Grillner, 1986; Mayer and Westbrook, 1984; Nowak et al., 1984), to the bathing medium also greatly reduced ventral root discharge in the caudal part and caused a similar reversible reduction in the amplitude of the membrane potential oscillations of motoneurons 1-2 segments caudal to the partition (mean, 29\%; range, 26-34\%; SEM, 1.7; $n=5$; see Fig. 7). In 2 further cases, the amplitude of the oscillations occurring in motoneurons recorded 8 and 9 segments caudal to the partition was unaffected by $1.8 \mathrm{mM} \mathrm{M \textrm {Mg } ^ { 2 + }}$. This suggests that these particular neurons did not receive NMDA receptor-mediated excitation. This may be because the oscillations recorded in cells this far from the partition are small and consist of relatively few components (cf. Fig. 5).

In 2 cases tested, the antagonist action of $\mathrm{Mg}^{2+}$ on these oscillations appeared to be voltage dependent. The injection of small positive biasing currents $(0.5-1.0 \mathrm{nA})$ into the motoneurons restored the amplitude of the oscillations to control values (see Fig. 13).

In summary, antagonists that act at NMDA receptors partially reduce the rhythmic descending excitation received by motoneurons during swimming. This suggests the existence of some rhythmically firing interneurons that use an amino acid transmitter, activate NMDA receptors present on motoneurons, and contribute to their excitatory drive during swimming.

\section{Antagonists acting at NMDA and non-NMDA receptors}

When the antagonist PDA, which can act at all 3 types of excitatory amino acid receptor in amphibians and mammals (Watkins and Evans, 1981) but in the lamprey acts predominantly at NMDA and kainate receptors (Dale and Grillner, 1986), was added $(2 \mathrm{~mm})$ to the caudal pool, rhythmic ventral root activity caudal to the partition was reversibly abolished, but the activity in the rostral pool was unaffected (Fig. 8). The membrane potential oscillations were greatly reduced (mean, $63 \%$; range, 44- 


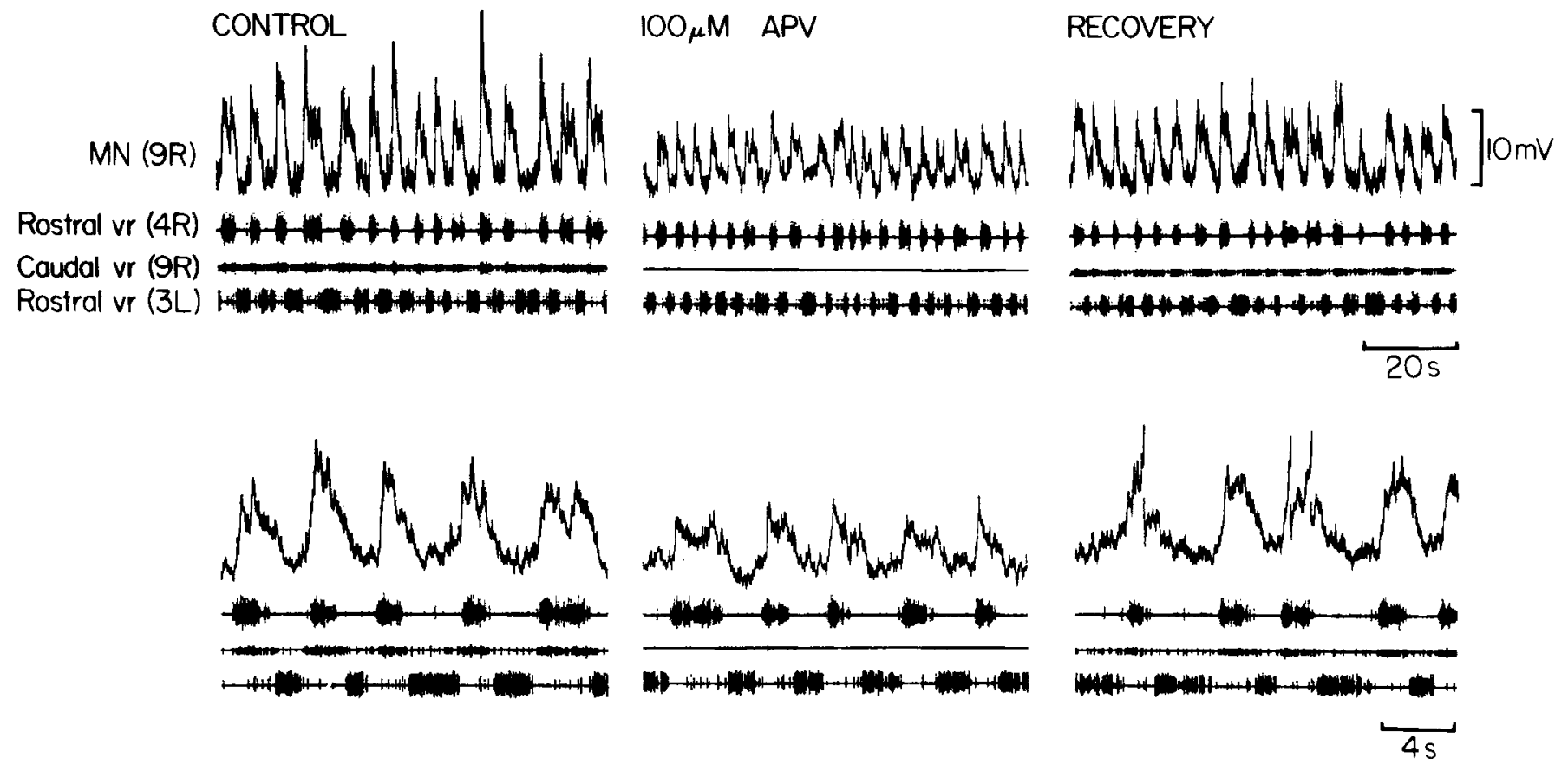

Figure 6. Effect of $100 \mu \mathrm{M}$ APV on oscillation amplitude. APV had its effect after 10 min of bath application, and nearly full recovery was obtained after 30 min of washing with control saline. The motoneuron was recorded 2 segments caudal to the partition. The presence of strychnine explains the tonic firing in the caudal ventral root. Records are shown at 2 different time bases.

$77 \%$; SEM, 7.5; $n=4$; see Fig. 8) in motoneurons recorded 28 segments caudal to the partition. KYAC, another antagonist that is also effective at all 3 excitatory amino acid receptors (Dale and Grillner, 1986; Ganong et al., 1983; Perkins and Stone, 1982), was even more potent. When applied at $2 \mathrm{~mm}$,
KYAC not only abolished ventral root activity in segments caudal to the partition (while having no effect on activity in the rostral pool), it also greatly reduced the amplitude of oscillations in motoneurons 1-9 segments caudal to the partition (mean, $84 \%$; range $75-92 \%$; SEM, $4.5 ; n=4$; Fig. 8). The effects of

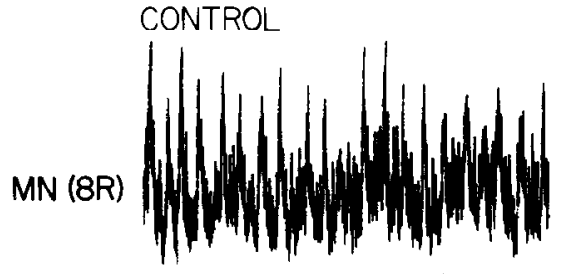

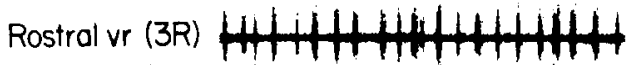
Caudal vr (8R) Rostral vr (3L)
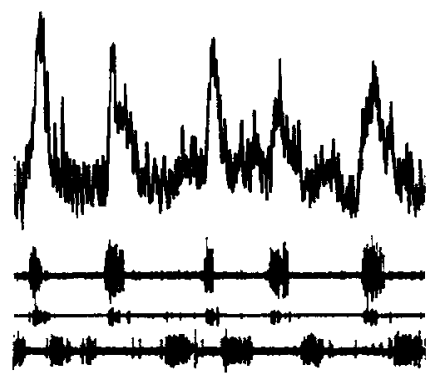

$$
\mathrm{Mg}^{2 *}
$$
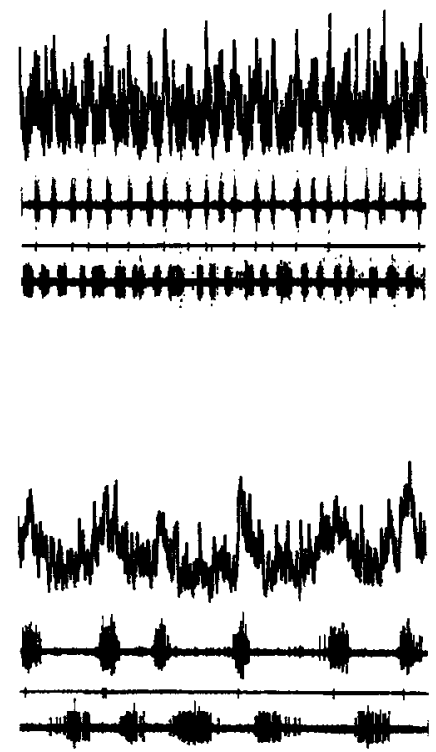

\section{RECOVERY}
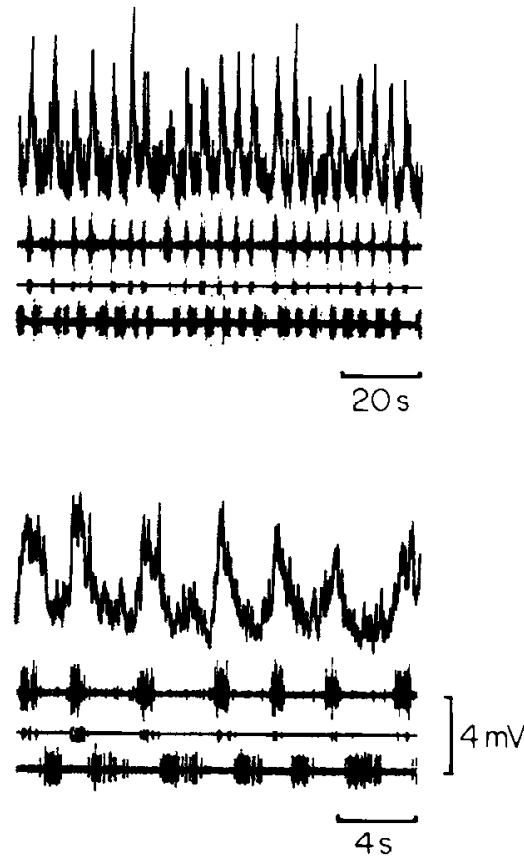

Figure 7. Effect of adding $1.8 \mathrm{~mm} \mathrm{Mg}^{2+}$ back to the saline on the amplitude of the descending excitatory drive. The effect of $\mathrm{Mg}^{2+}$ is shown after $12 \mathrm{~min}$ of application, and full recovery occurred after some $25 \mathrm{~min}$ of washing with control saline. The motoneuron was recorded 2 segments caudal to the partition. 

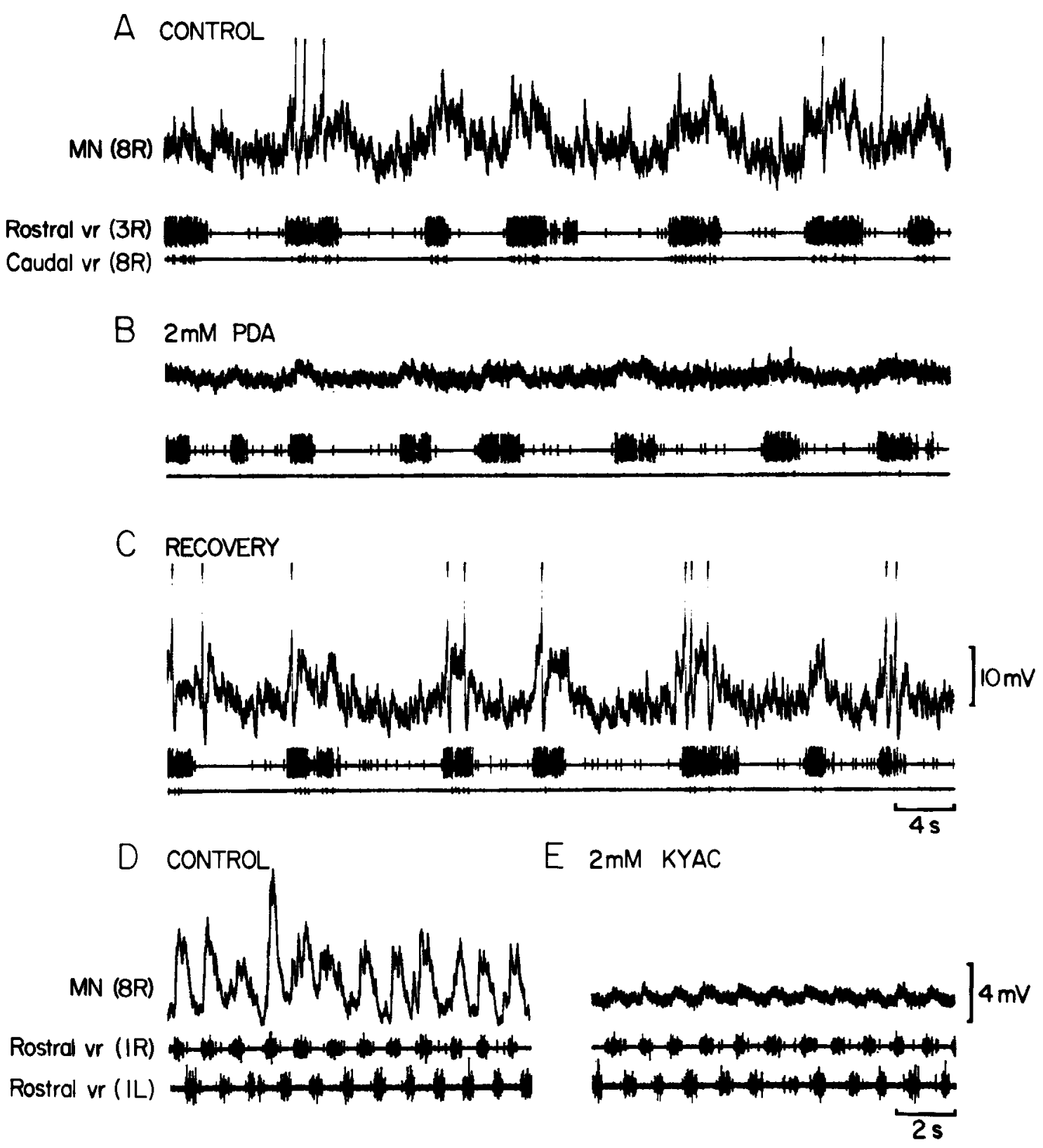

Figure 8. Effect of PDA and kynurenic acid $(K Y A C)$ on the descending excitatory drive. $A$, Control records from a motoneuron recorded 2 segments caudal to the partition. $B$, Ten minutes after the application of the PDA. $C$, Recovery after some 20 min of washing. $D$, Control records from a motoneuron recorded 1 segment caudal to the partition of a different preparation in a $20 \mathrm{mM} \mathrm{Ca}^{2+}$, strychnine, and $0 \mathrm{Mg}^{2+}$ saline. $E$, Effect of $8 \mathrm{~min}$ of kynurenic acid application.

KYAC were more difficult to reverse than those of the other antagonists, and only a partial recovery in oscillation amplitude was obtained even after some $45 \mathrm{~min}$ of washing with control saline.

Some of the descending excitatory drive for swimming therefore seems to be generated by neurons that fire rhythmically and release a transmitter acting at non-NMDA receptors. These could be either the same neurons that activate motoneuron NMDA receptors or a separate class of neurons that activate only non-NMDA receptors. The excitation mediated by these 2 receptor classes may account for the whole of the descending excitatory drive generated within the spinal cord and received by motoneurons.

\section{Excitatory drive in premotor interneurons}

Lateral interneurons-identified by their large, laterally placed cell body and fast-conducting, ipsilaterally descending axon (Rovainen, 1974)-and CC interneurons-identified by their crossed and caudally projecting axon (Buchanan, 1982) - are known inhibitory premotor interneurons that are active during swimming in the lamprey. Recordings from 5 lateral interneurons made caudal to the partition of a rostrally driven preparation showed that all received oscillations that persisted in salines containing $20 \mathrm{mM} \mathrm{Ca}^{2+}$ and $5 \times 10^{-6} \mathrm{M}$ strychnine (Fig. 9). Recordings from $8 \mathrm{CC}$ interneurons were also made. Seven $\mathrm{CC}$ interneurons received oscillations that, in 6 neurons, occurred in phase with 

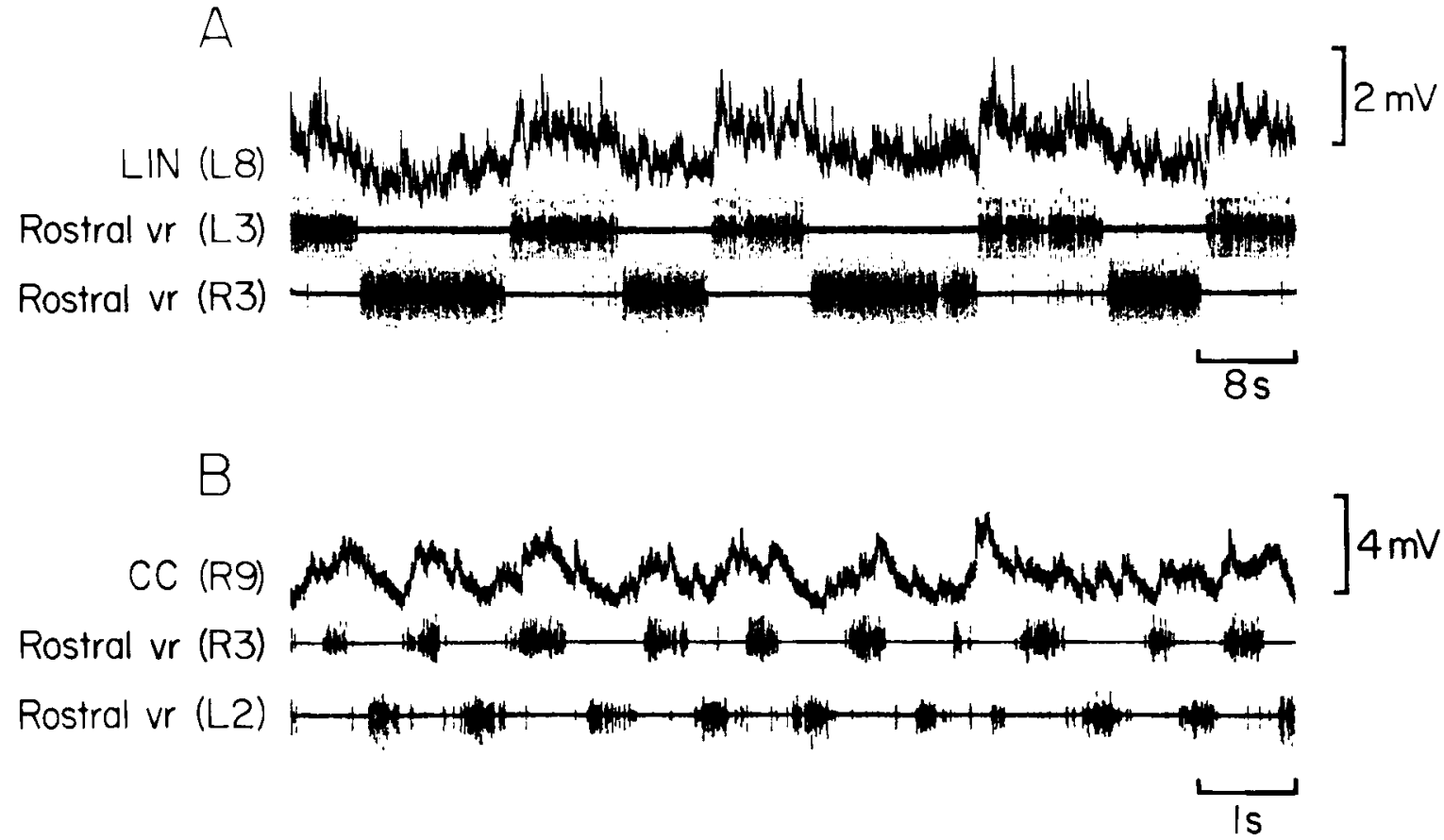

Figure 9. Descending excitatory drive recorded in a lateral interneuron $(L I N)$ recorded 1.5 segments caudal to the partition and a CC interneuron (CC) recorded 2 segments caudal to the partition of a different preparation. Both traces show oscillations occurring in salines containing 20 mm $\mathrm{Ca}^{2+}$, strychnine and $0 \mathrm{Mg}^{2}$

the ipsilateral ventral root discharge (Fig. 9); the seventh $\mathrm{CC}$ interneuron received oscillations that occurred in phase with the contralateral ventral root discharge. Buchanan (1982) reported that, while the majority of $\mathrm{CC}$ interneurons received excitation in phase with the ipsilateral ventral root discharge, excitatory $\mathrm{CC}$ interneurons could be coactive with the contralateral ventral root. One further $C \mathrm{C}$ interneuron received apparently random synaptic potentials bearing little relation to the
A

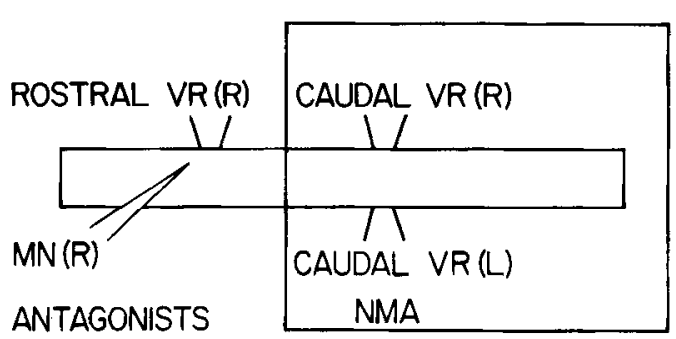

C

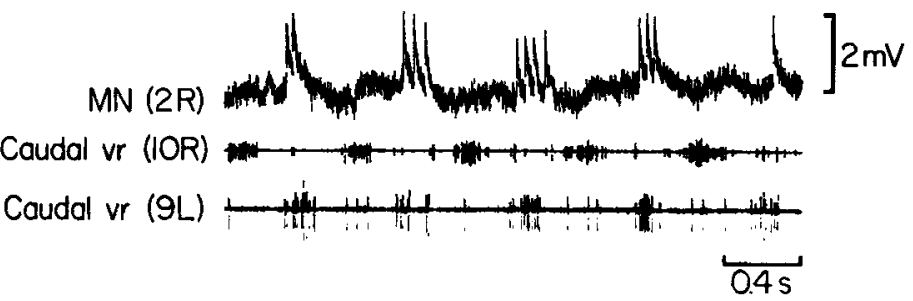

$\mathrm{B}$

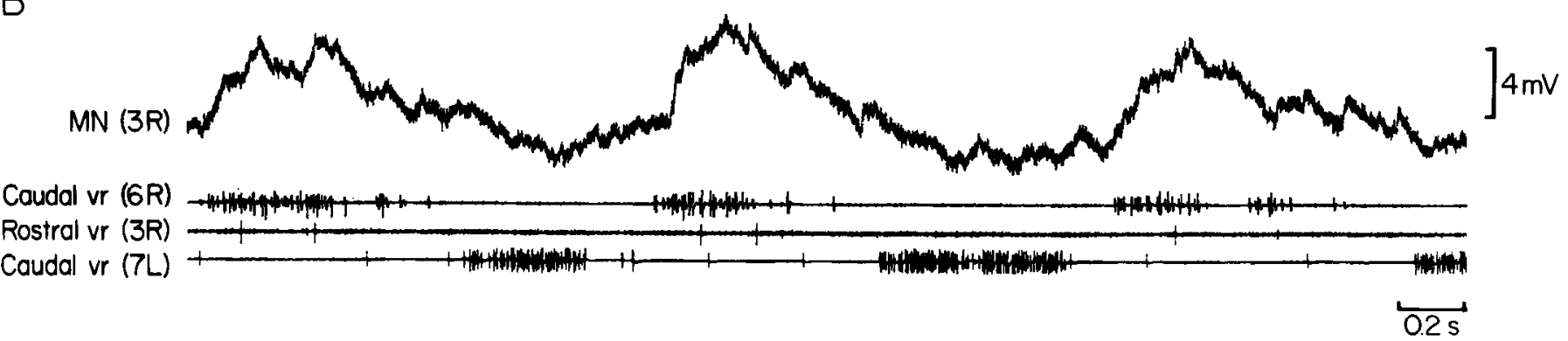

Figure 10. The caudally driven partitioned preparation. A, Diagram of the preparation, labeling of the electrodes, and numbering of the segments follow the same scheme as that for the rostrally driven preparation. $B$, Oscillations recorded in a motoneuron 1 segment rostral to the partition in a saline containing $5 \times 10^{-6} \mathrm{M}$ strychnine, $20 \mathrm{mM} \mathrm{Ca}^{2+}$, and $0 \mathrm{Mg}^{2+} . C$, Chloride-reversed, strychnine-resistant IPSPs occurring in phase with the contralateral ventral root in a motoneuron 3 segments rostral to the partition of a different preparation. Note the very small amplitude of the excitatory drive in this neuron. 


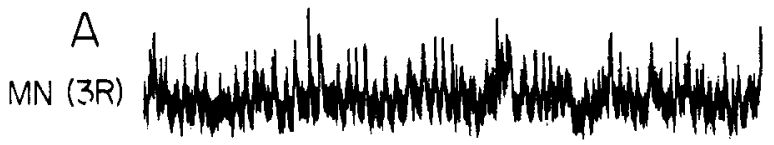

Coudal vr (7R)

Caudal vr $(7 L)$

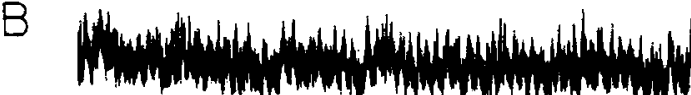

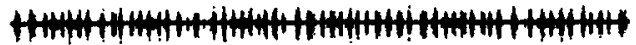

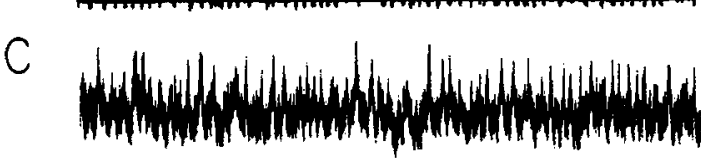

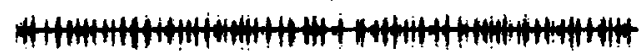

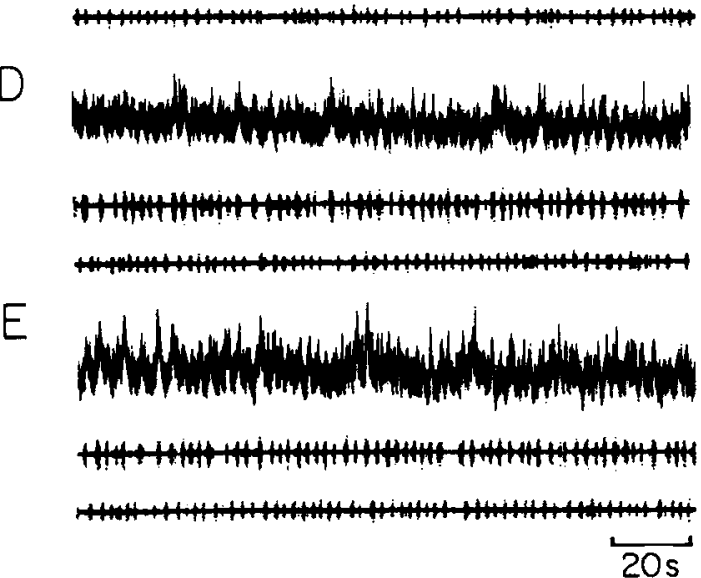

CONTROL
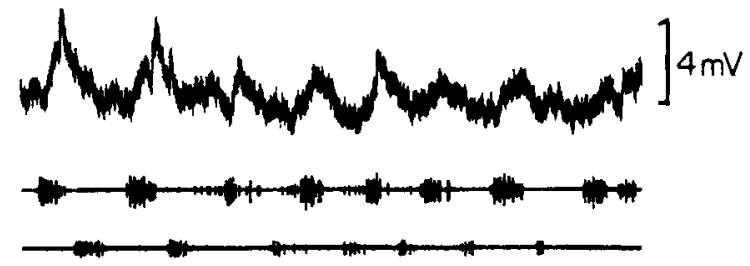

APV
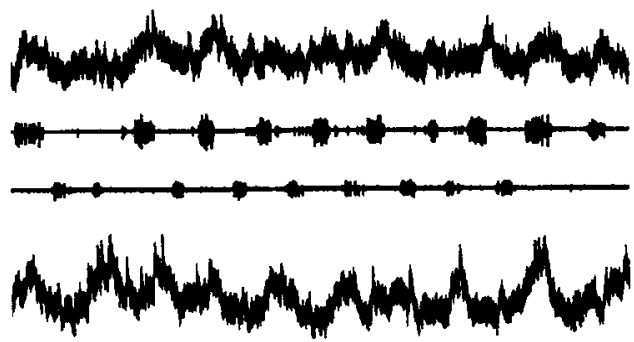

RECOVERY
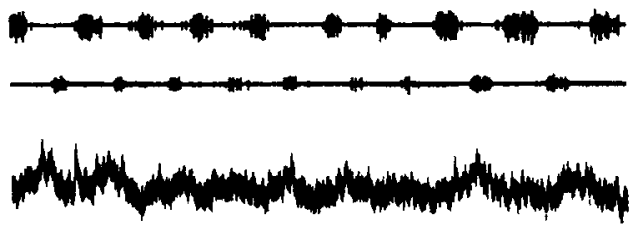

$\mathrm{Mg}^{2+}$

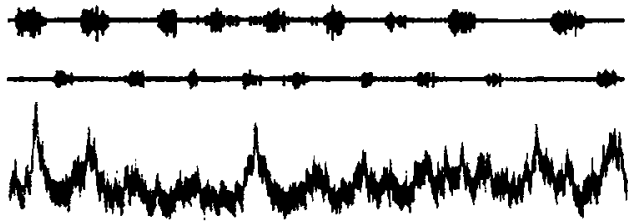

RECOVERY

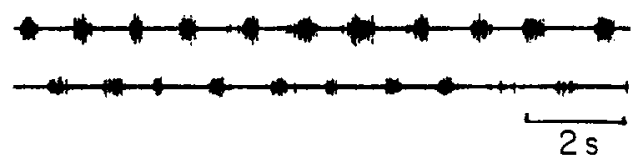

Figure 11. Effect of the NMDA antagonists APV and $\mathrm{Mg}^{2+}$ on the ascending excitation. $A$, Control records; $B, 12 \mathrm{~min}$ of $100 \mu \mathrm{M}$ APV; $C, 45$ min after the APV was washed out of the bath; $D, 12$ min of $1.8 \mathrm{mM} \mathrm{Mg}^{2+}$; and $E, 20$ min after the $\mathrm{Mg}^{2+}$ was washed out of the bath. Each set of traces is shown at 2 different time bases; the motoneuron was recorded 1 segment rostral to the partition.

activity of the rostral spinal cord. This suggests that lateral interneurons and $\mathrm{CC}$ interneurons receive similar descending drive to motoneurons; however, no attempt was made to characterize the pharmacological properties of the excitation that they received.

\section{Caudally driven partitioned preparations}

In order to determine whether motoneurons received ascending excitatory drive during swimming, a series of experiments was performed in which only the caudal-most 6-8 segments of a piece of spinal cord were exposed to NMA (Fig. 10A). Fictive swimming was therefore activated in these segments but not in segments rostral to the partition, which were continually superfused with control saline.

In such preparations the first ventral root rostral to the partition could sometimes fire a few spikes rhythmically in phase with the caudal ipsilateral ventral root, and motoneurons 1-3 segments rostral to the partition were observed to receive oscillations in phase with the caudal ventral roots (Fig. 10). The oscillations seemed to consist of alternating excitatory and inhibitory phases and persisted in $20 \mathrm{mM} \mathrm{Ca}^{2+}$ salines apparently unchanged in amplitude. Addition of $5 \times 10^{-6} \mathrm{M}$ strychnine to the bathing medium apparently blocked all the inhibition; in a few cells $(n=5)$, however, the use of $\mathrm{KCl}$ electrodes revealed some small IPSPs (reversed by chloride injection), which oc- curred in phase with the contralateral ventral root (Fig. 10C). Since these ascending IPSPs were resistant to prolonged exposure to strychnine, they may be mediated by some transmitter other than glycine. The oscillations remaining in the presence of strychnine ranged from 1 to $6 \mathrm{mV}$, being generally much smaller than the oscillations seen in motoneurons recorded in corresponding positions caudal to the partition of a rostrally driven preparation. The peak depolarization of the oscillation (measured in salines containing strychnine) occurred at a phase value $\phi=0.27(\mathrm{SD}=0.09 ; n=40)$ with respect to the onset of the ipsilateral ventral root burst. This is significantly $(p<$ 0.001 ) later in the swimming cycle than the occurrence of the peak depolarization of both the descending excitation $(0.20)$ and motoncuron excitation during fictive swimming $(0.21)(\mathrm{Bu}-$ chanan and Cohen, 1982).

In addition to those motoneurons that received clear oscillations that were phase related to the caudal ventral roots, 5 out of the 30 motoneurons sampled received apparently random membrane potential variations having little or no consistent relation to the caudal ventral roots.

The oscillations, like those in the rostrally driven preparations, may have been monosynaptic. They persisted in $20 \mathrm{~mm}$ $\mathrm{Ca}^{2+}$, and local application of $50 \mathrm{~mm}$ glycine droplets in salines containing $5 \mathrm{mM} \mathrm{Ca}^{2+}(n=3)$ to the first segment rostral to the partition blocked the weak ventral root discharge of that seg- 


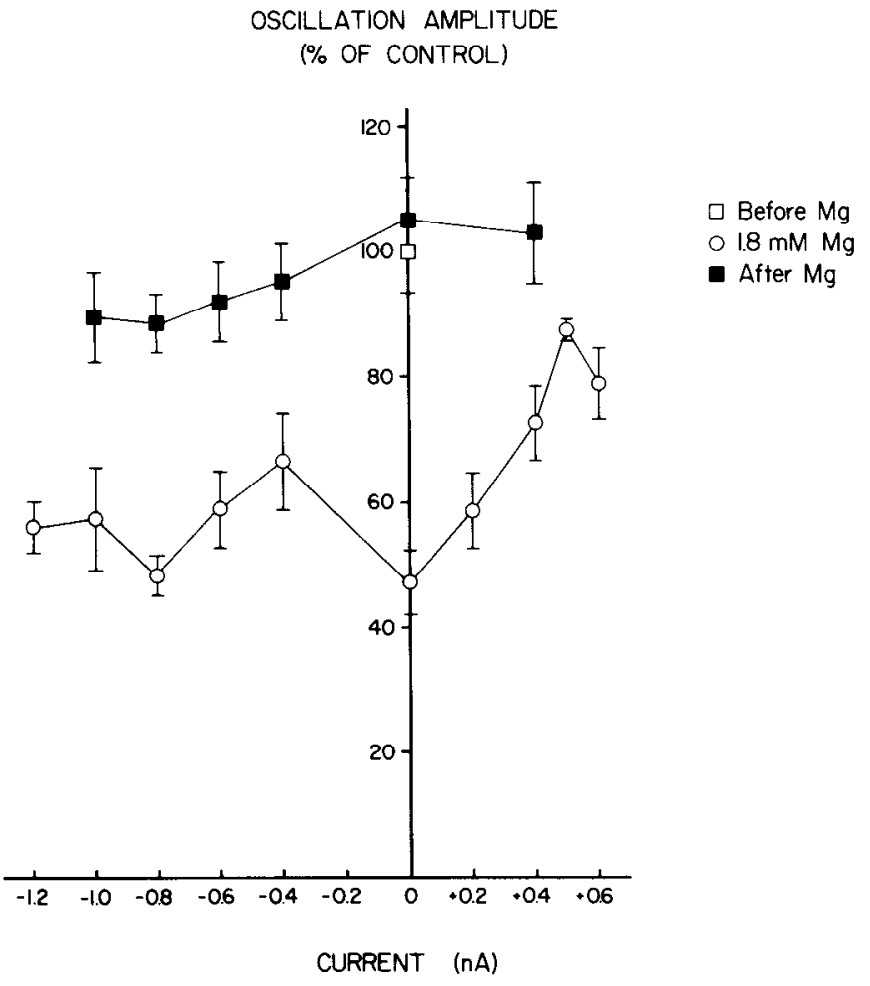

Figure 12. Voltage dependence of the antagonism of the ascending excitation by $\mathrm{Mg}^{2+}$ : amplitude of the oscillations before the addition of $\mathrm{Mg}^{2+}$ to the bathing medium ( $\square$ ), after the addition of $\mathrm{Mg}^{2+}(\mathrm{O})$, and after the removal of $\mathrm{Mg}^{2+}(\square)$. The motoneuron was recorded $1.5 \mathrm{seg}-$ ments rostral to the partition in a saline containing strychnine and 20 $\mathrm{mm} \mathrm{Ca}^{2+}$. The amount of injected current is shown rather than the cell's resting potential due to uncertainty about the electrode balance.

ment but had little or no effect on the oscillations recorded in a motoneuron one segment more rostral (cf. Fig. 3). Application of the same-sized glycine droplet to the segment of the motoneuron itself caused a depolarization of the motoneuron and a great reduction of the oscillation amplitude. Although these results must be interpreted with caution, taken together they suggest that at least a substantial proportion of the ascending excitation is monosynaptic.

The oscillations in rostral motoneurons were dependent on the activity of the caudally driven segments. If this was abolished by the addition of TTX into the caudal pool $(n=4)$, the rhythmic alternation of ventral root bursts ceased and was replaced by tonic activity and then complete silence. In parallel with these effects, the oscillations in rostral motoneurons were replaced by a depolarizing phase consisting of high-frequency synaptic potentials that gradually declined to a complete cessation of synaptic activity ( $c f$. Fig. $2 A$ ). The ascending excitation would therefore appear to be mediated by the actions of neurons located in the caudally driven segments, which fire rhythmically and have ascending axons. These axons may be short since no oscillations were seen in motoneurons more than 3 segments rostral to the partition $(n=5)$.

\section{Pharmacology of the ascending excitatory drive}

All pharmacological experiments were performed in salines containing $5 \times 10^{-6} \mathrm{M}$ strychnine and $20 \mathrm{mM} \mathrm{Ca}^{2+}$ in order to block inhibition and prevent strychnine-induced spontaneous activity, which appeared to be more common in caudally driven preparations.
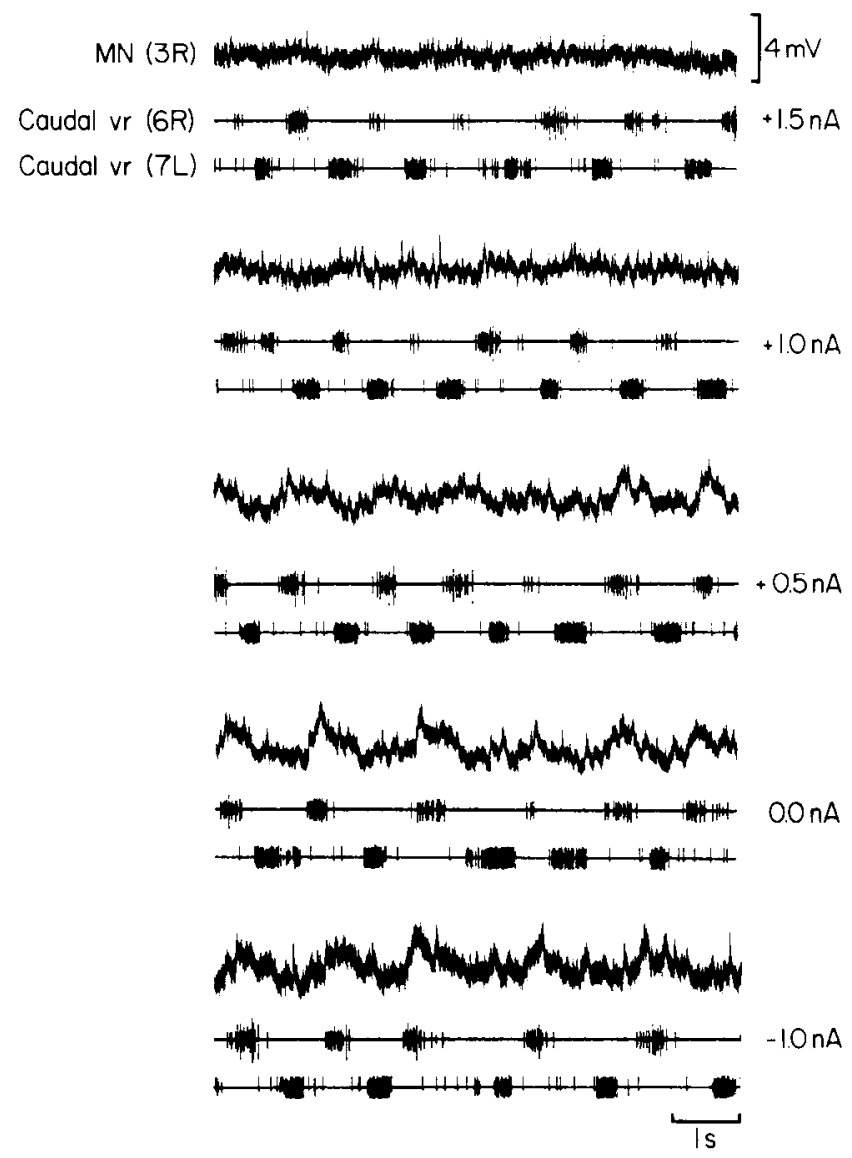

Figure 13. Ascending excitatory drive recorded in a motoneuron 1 segment rostral to the partition in a saline containing strychnine, 20 $\mathrm{mM} \mathrm{Ca}{ }^{2+}$, and $1.8 \mathrm{mM} \mathrm{Mg}^{2+}$. Small positive biasing currents could completely suppress these oscillations. The resting potential of the cell was $72 \mathrm{mV}$, and the injection of $+1.0 \mathrm{nA}$ depolarized the cell by 22 $\mathrm{mV}$ (after electrode was balanced inside the cell using $200 \mathrm{msec}+1.0$ $\mathrm{nA}$ square pulses).

\section{Effect of antagonists}

APV, $100 \mu \mathrm{M}$, applied to the bathing medium surrounding the rostral segments caused a mean reduction of $40 \%$ (SEM, 3.4; range, $30-46 \% ; n=4$ ) in the amplitude of oscillations recorded in motoneurons 1-2 segments rostral to the partition (Fig. 11). APV had no discernible effect on the burst frequency or intensity of the activity in the caudal driven segments. $\mathrm{Mg}^{2+}$, a specific NMDA antagonist, at $1.8 \mathrm{~mm}$, also reduced the oscillation amplitude by a mean of $50 \%$ (SEM, 7.3 ; range, $28-59 \% ; n=4)$ in motoneurons 1-2 segments rostral to the partition (Fig. 11). The effect of these antagonists on the ascending oscillations was greater than on the descending oscillations. However, only in the case of $\mathrm{Mg}^{2+}$ was this difference statistically significant $(p<0.05)$. This suggests that a greater proportion of the ascending excitation may be mediated by a transmitter acting at NMDA receptors compared to the descending excitation.

The antagonistic effect of $\mathrm{Mg}^{2+}$ was voltage sensitive: in 3 cases it was possible to reverse the blockade by the injection of small amounts of tonic current, which nearly restored the amplitude of the oscillations to their control value (Fig. 12). This is consistent with findings that $\mathrm{Mg}^{2+}$ confers voltage sensitivity on the NMDA receptor channel by blocking it in a voltagedependent manner (Mayer and Westbrook, 1985; Mayer et al., 1984; Nowak, et al., 1984). In 2 other cases, tonic current injection had intriguing effects on the oscillations. In 1 motoneu- 

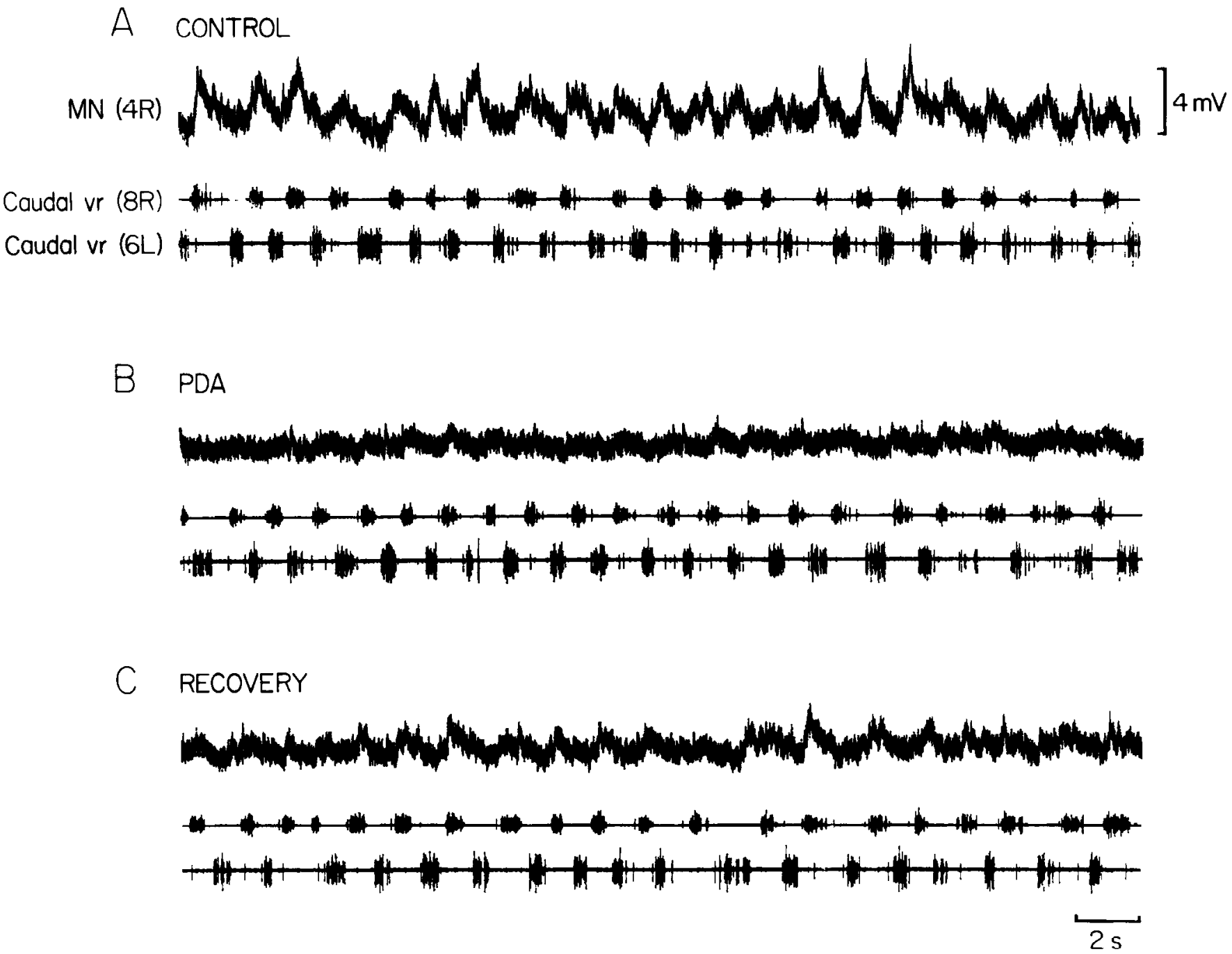

Figure 14. Effect of $2 \mathrm{~mm}$ PDA on the ascending excitation. $A$, Control records showing the excitatory oscillations in a motoneuron 1.5 segments rostral to the partition. $B$, Ten minutes after the addition of $2 \mathrm{~mm}$ PDA to the bathing medium. $C$, Partial recovery obtained after some 25 min of washing with control saline.

ron that apparently received no oscillations, injection of -0.5 to $-1.0 \mathrm{nA}$ of current revealed oscillations that occurred in phase with the ipsilateral caudal ventral root discharge. In another cell, the oscillations could be completely abolished by the injection of +1.0 nA of current (Fig. 13). Since the injection of $1.0 \mathrm{nA}$ of current depolarized the motoneuron by only $22 \mathrm{mV}$, these effects are unlikely to have been caused by the current injections moving the cell towards or away from the EPSP reversal potential. For amino acid-mediated excitation, this appears to be around $0 \mathrm{mV}$ (Mayer and Westbrook, 1985).

These results were obtained in saline containing $\mathrm{Mg}^{2+}$, and they are consistent with the proposal that the conductance underlying these oscillations is voltage sensitive and may result from the activation of NMDA receptors by the endogenous transmitter. Although such effects were never seen in $\mathbf{M g}^{\mathbf{2 +}}$-free salines, this was not tested in these 2 cases, and it is not possible to say whether they would have occurred in $\mathrm{Mg}^{2+}$-free salines or whether they were dependent on a voltage-sensitive blockade of NMDA receptors by $\mathbf{M g}^{2+}$.

Application of $2 \mathrm{~mm}$ PDA, an antagonist for all 3 types of excitatory amino acid receptor, caused a mean reduction of $71 \%$ in the oscillation amplitude (SEM, 8.0; $n=2$; Fig. 14), suggesting that the endogenous transmitter may also activate non-NMDA receptors in addition to NMDA receptors.
The ascending excitation therefore seems to be generated by neurons which have short ascending axons, fire rhythmically during swimming and release a transmitter which activates NMDA and non-NMDA receptors on motoneurons. This excitation occurred significantly later in the cycle than the descending excitation.

\section{Discussion}

These experiments were designed to investigate the excitatory drive for motoneurons generated within the spinal cord by populations of neurons with projecting axons. They do not test the possibility that part of the synaptic drive might be generated by a few large neurons with very long axons located in circumscribed regions of the CNS and making widespread synaptic connections (lateral interneurons) or by local intrasegmental interneurons. However, if such neurons do generate part of the excitatory drive, their contribution (in terms of quantity) may be small since the amplitude of oscillations recorded just caudal to the partition can be very similar to those recorded in motoneurons during fictive locomotion (Buchanan and Cohen, 1982; Kahn, 1982; Russell and Wallén, 1983; Wallén et al., 1985). Rovainen $(1985,1986)$, who has addressed the problem of longitudinal coordination with similar techniques to those used here, obtained evidence suggesting the existence of short axon 
inhibitory commissural cells (similar in length to the "long" axons described here) and excitatory neurons with long ascending crossed axons that are important in the longitudinal coordination of swimming. These results are complementary to those presented here.

\section{Descending excitatory drive}

In rostrally driven preparations, motoneurons caudal to the partition received rhythmic excitation that occurred in phase with the ipsilateral ventral root discharge. These oscillations were dependent on the activity occurring in the rostral pool and ceased when this was abolished by the addition of TTX. They persisted in salines containing $20 \mathrm{mM} \mathrm{Ca}^{2+}$, and their amplitude was little affected by local application of glycine to regions lying between the caudally recorded motoneuron and the rostral active part. These observations suggest that the oscillations were largely monosynaptic and were generated by rhythmically firing neurons located in the rostral segments that are part of the swimming central pattern generator and have long descending axons.

Since the amplitude of these oscillations was partially reduced by APV and $\mathrm{Mg}^{2+}$, and greatly reduced by $\mathrm{PDA}$ and $\mathrm{KYAC}$, the oscillations would appear to be mediated by a transmitter acting at both NMDA and non-NMDA receptors. Another transmitter could possibly be involved in mediating these oscillations since there was a small remnant left during PDA and KYAC application. This may be unlikely because these antagonists are probably competitive in action (Watkins et al., 1981) and would therefore not be expected to abolish the PSPs completely in view of the presumably high concentration of transmitter in the synaptic cleft. The $60-80 \%$ depression in amplitude seen here is very similar in size to the effects of similar antagonists on other synaptic potentials (Crunelli et al., 1982; Dale and Grillner, 1986; Dale and Roberts, 1985) considered to be wholly mediated by excitatory amino acid transmitters. The observed oscillations in motoneuron resting potential would therefore seem to be produced by rhythmically firing interneurons rcleasing a transmitter that acts at NMDA receptors, presumably generating slow time course EPSPs (Dale and Grillner, 1986; $c f$. Dale and Roberts, 1985), and kainate/quisqualate receptors, presumably generating fast time course EPSPs (Dale and Grillner, 1986). The peak depolarization of the descending excitation occurred at the same point in the swimming cycle as the peak depolarization of membrane potential in motoneurons during fictive swimming (Buchanan and Cohen, 1982; Kahn, 1982). This suggests that the descending excitation is sufficient to account for at least the start of the excitation received by motoneurons during swimming.

\section{Ascending excitatory drive}

Motoneurons also received ascending rhythmic excitation in caudally driven preparations. This excitation was slightly phasedelayed in relation to the ipsilateral caudal ventral roots, and it seemed to depend on activation of the caudal segments. These oscillations persisted in $20 \mathrm{mM} \mathrm{Ca}^{2+}$ salines and were unaffected by the local application of glycine between the caudal active part and the recorded motoneuron. This suggests the existence of neurons situated in the caudal segments that fire rhythmically and have ascending axons. The ascending excitation, like the descending, seemed to depend on the actions of a transmitter acting at NMDA and non-NMDA receptors. $\mathrm{Mg}^{2+}$ and APV seemed to have a greater effect on the ascending oscillations as opposed to the descending. This may mean that a larger part of the ascending oscillations is mediated by NMDA receptors.

The peak depolarization of the ascending excitation occurred significantly later in the cycle compared to both the descending excitation and the excitation during fictive swimming. Since the excitation received by motoneurons during swimming in an intact lamprey would presumably be a summation of both the descending and ascending drive, this would have the effect of increasing the duration of excitation during the swimming cycle, possibly making it easier to trigger the burst of the next cycle.

Whereas the descending excitation seemed to extend at least 9 segments from the active part, the ascending excitation seemed to extend only 2 or 3 segments. This seems appropriate: Synaptic drive over 2 or 3 segments rostrally would distribute excitation to the spinal network but would not disturb longitudinal coordination by occurring too late in the swimming cycle. If the ascending excitation is also mediated by the NMDA receptors to a greater extent, this would again be appropriate. Since the NMDA receptor-mediated EPSPs are slow in time course (Dale and Grillner, 1986; Dale and Roberts, 1985), this would result in the distribution of slow excitation rostrally, rather than faster excitation possibly containing timing cues that might disturb the firing of neurons in more rostral segments and hence the longitudinal coordination.

Voltage sensitivity conferred by $\mathrm{Mg}^{2+}$

When $\mathrm{Mg}^{2+}$ was added back to the saline, it depressed the amplitude of both the ascending and descending oscillations in a voltage-dependent manner. This was particularly marked for the ascending oscillations, as injection of small tonic biasing currents could restore them to control amplitudes. The exogenous activation of NMDA receptors can lead to the production of TTX-resistant oscillations in motoneurons and other propriospinal neurons (Sigvardt et al., 1985; Wallén and Grillner, 1985). These oscillations require the presence of $\mathrm{Mg}^{2+}$ (Grillner and Wallén, 1985), which appears to confer voltage sensitivity on NMDA receptor channels (Mayer et al., 1984; Nowak et al., 1984). It is not clear what role these membrane properties play during naturally evoked fictive swimming in the absence of exogenous NMDA receptor agonist. The lamprey spinal cord can still generate a rhythmic motor output in salines lacking $\mathrm{Mg}^{2+}$, but the rhythm is much more variable. This suggests that, while not essential, these properties may play some role in pattern gencration (Brodin et al., 1985b). The evidence presented here that $\mathrm{Mg}^{2+}$ confers voltage sensitivity on the oscillations is the first to suggest that the release of an endogenous transmitter during swimming can activate these membrane properties in the absence of exogenous agonist and that they are important in the generation of the swimming motor pattern in the intact animal. During swimming, NMDA receptors appear to be activated rhythmically rather than tonically (as occurs when fictive swimming is evoked by a bath-applied agonist). This would tend to reinforce any inherent tendency of the membrane to oscillate.

\section{Possible anatomical substrate}

The experiments also suggest a possible anatomy for the neurons that generate the excitatory drive. The descending excitation could extend for a distance of about 10 segments, whereas the ascending excitation may extend only 2 or 3 segments. Furthermore, the descending drive could be abolished by ipsilateral lesions. The excitation in the lamprey could be mediated by the effects of one or several classes of neuron. If only one type of neuron is involved, they may have descending ipsilateral axons about 10 segments long, short ascending collaterals about 2 or 3 segments long, and release a transmitter acting at both NMDA and non-NMDA receptors on the postsynaptic membrane. Under this hypothesis, the specificity of action would lie purely in the receptors present on the postsynaptic membrane. A precedent for this hypothesis already exists. In the Xenopus embryo there is evidence for a class of excitatory interneuron which can release an amino acid transmitter which acts at both NMDA and non-NMDA receptors at the same synapse (Dale and Roberts, 1985), and in the lamprey evidence exists for similar dualcomponent synapses (Dale and Grillner, 1986; J. T. Buchanan 
and N. Dale, unpublished observations). Of course, it is possible that there are separate classes of cells mediating the descending and ascending excitation and/or the activation of the 2 receptor types. Indeed, it may be easier to explain the differences between the ascending and descending excitation in phasing and proportion of excitation that is mediated by NMDA receptors by postulating separate neuronal classes generating the 2 types of synaptic drive. Only further experimentation - and, in particular, paired intracellular recordings - will resolve these questions.

\section{Comparison with the Xenopus embryo}

Striking similarities have now emerged between the control of swimming in the Xenopus embryo and the lamprey. In both animals, bath-applied agonists acting at either NMDA or kainate receptors can activate swimming (Brodin et al., 1985; Dale and Roberts, 1984; Grillner et al., 1981; Poon, 1980). The natural activation of swimming in the embryo appears to depend on a transmitter acting at NMDA and kainate receptors (Dale and Roberts, 1983, 1984), and the same seems to be true for the lamprey (Brodin and Grillner, 1985). In the Xenopus embryo, the excitatory drive for motoneurons during swimming is generated by a class of interneurons that fire rhythmically in phase with the motoneurons they excite, make ascending and descending connections, and use an amino acid transmitter that acts at 2 types of receptors generating slow NMDA receptormediated EPSPs and fast kainate/quisqualate receptor-mediated EPSPs (Dale and Roberts, 1985). In the lamprey, not only do motoneurons receive EPSPs of similar time course and pharmacology (Dale and Grillner, 1986), but the results presented here suggest that a major part of the excitatory drive for swimming is generated by a class of interneurons that fire rhythmically and use an amino acid transmitter that acts at NMDA and kainate/quisqualate receptors. It would therefore appear that the central pattern generators for swimming in these 2 animals share several basic mechanisms. An important feature of the model for swimming proposed for the Xenopus embryo central pattern generator (for which indirect evidence exists) is that the excitatory interneurons form a self-excitatory network that reverberates and is crucial for the generation and maintenance of swimming (Dale and Roberts, 1985; Roberts et al., 1984, 1985). Such a mechanism could also be of importance in the lamprey, although as yet there is little evidence to support its existence.

\section{Evolutionary implications}

These striking parallels between the Xenopus embryo and the lamprey demonstrate the virtue of working with simple preparations and are remarkable for 2 reasons. First, the swimming pattern of the 2 animals is very different in frequency, burst duration, and longitudinal coordination (Kahn et al., 1982; Wallén and Williams, 1984). Second, the lamprey is an Agnathan vertebrate, a modern-day descendant of the very first group of vertebrates to evolve. The evolutionary distance separating the 2 may be a few hundred million years, and there seems no $a$ priori reason why any of the mechanisms underlying the operation of swimming in the central pattern generator in the Agnatha should be preserved in the Amphibia. Yet these results indicate that at least some are and suggest a hitherto unperceived unity in a seemingly disparate field. If these mechanisms have been conserved in evolutionary process leading from the $\mathrm{Ag}$ natha to the Amphibia, perhaps they are also conserved in higher animals and are important features underlying the control of movements in mammals too.

\section{References}

Ault, B., R. H. Evans, A. A. Francis, D. J. Oakes, and J. C. Watkins (1980) Selective depression of excitatory amino acid induced depolarizations by magnesium ions in isolated spinal cord preparations. J. Physiol. (Lond.) 307: 413-428.
Berry, A. S., and V. W. Pentreath (1976) Criteria for distinguishing between monosynaptic and polysynaptic transmission. Brain Res. 105: 1-20.

Brodin, L., and S. Grillner (1985) The role of putative excitatory amino acid neurotransmitters in the initiation of locomotion in the lamprey spinal cord. I. The effects of excitatory amino acid antagonists. Brain Res. 360: 139-148.

Brodin, L., S. Grillner, and C. M. Rovainen (1985a) NMDA, kainate and quisqualate receptors and the generation of fictive locomotion in the lamprey spinal cord. Brain Res. 325: 302-306.

Brodin, L., S. Grillner, and P. Wallén (1985b) The effects of magnesium ions, TEA and gallamine on NMA-induced rhythmic activities in the lamprey spinal cord in vitro. Acta Physiol. Scand. (Suppl. 542) 124: 275 .

Buchanan, J. T. (1982) Identification of interneurons with contralateral caudal axons in the lamprey spinal cord: Synaptic interactions and morphology. J. Neurophysiol. 47: 961-975.

Buchanan, J. T., and A. H. Cohen (1982) Activities of identified interneurons, motoneurons, and muscle fibers during fictive swimming in the lamprey and effects of reticulospinal and dorsal cell stimulation. J. Neurophysiol. 47: 948-960.

Crunelli, V., S. Forda, G. L. Collingridge, and J. S. Kelly (1982) Intracellular recorded synaptic antagonism in the rate dentate gyrus. Nature $300: 450-452$.

Dale, N. (1985) Reciprocal inhibitory interneurones in the Xenopus embryo spinal cord. J. Physiol. (Lond.) 363: 61-70.

Dale, N., and S. Grillner (1986) Dual-component synaptic potentials in the lamprey mediated by excitatory amino acid receptors. J. Neurosci. 6: 2653-2661.

Dale, N., and A. Roberts (1983) The effects of excitatory amino acid antagonists on swimming in Xenopus embryos. J. Physiol. (Lond.) 336: 62P-63P.

Dale, N., and A. Roberts (1984) Excitatory amino-acid receptors in Xenopus embryo spinal cord and their role in the activation of swimming. J. Physiol. (Lond.) 348: 527-543.

Dale, N., and A. Roberts (1985) Dual-component amino acid-mediated synaptic potentials: Excitatory drive for swimming in Xenopus embryos. J. Physiol. (Lond.) 363: 35-59.

Davies, J., A. A. Francis, A. W. Jones, and J. C. Watkins (1981) 2-Amino-5-phosphonovalerate (2-APV), a potent and selective antagonist of amino acid-induccd and synaptic excitation. Neurosci. Lett. 21: 77-81.

Delcomyn, F. (1980) Neural basis of rhythmic behaviour in animals. Science 210: 492-498.

Feldman, A. G., and G. N. Orlovsky (1975) Activity of interneurons mediating reciprocal Ia inhibition during locomotion. Brain Res. 84 : 181-194.

Ganong, A. H., T. H. Lanthorn, and C. W. Cotman (1983) Kynurenic acid inhibits synaptic and amino acid induced responses in the rat hippocampus and spinal cord. Brain Res. 273: 170-174.

Grillner, S., and P. Wallèn (1985) The ionic mechanisms underlying NMDA receptor-induced, TTX-resistant membrane potential oscillations in lamprey neurones active during locomotion. Neurosci. Lett. 60: 289-294.

Grillner, S., A. McClcllan, K. Sigvardt, P. Wallén, and M. Wilén (1981) Activation of NMDA-receptors elicits "fictive locomotion" in lamprey spinal cord in vitro. Acta Physiol. Scand. 113: 549-551.

Kahn, J. A. (1982) Patterns of synaptic inhibition in motoneurones and interneurones during fictive swimming in lamprey as revealed by $\mathrm{Cl}$ injections. J. Comp. Physiol. 147: 189-194.

Kahn, J. A., A. Roberts, and S. M. Kashin (1982) The neuromuscular basis of swimming movements in embryos of the amphibian Xenopus laevis. J. Exp. Biol. 99: 175-184.

Mayer, M. L., and G. L. Westbrook (1985) The action of N-methylD-aspartic acid on mouse spinal neurones in culture. J. Physiol. (Lond.) 361: 65-90.

Mayer, M. L., G. L. Westbrook, and P. B. Guthrie (1984) Voltagedependent block by $\mathbf{M g}^{2+}$ and NMDA responses in spinal cord neurones. Nature 309: 261-263.

Nowak, L., P. Bregestovski, P. Ascher, A. Herbert, and A. Prochiantz (1984) Magnesium gates glutamate-activated channels in mouse central neurones. Nature 307: 462-465.

Perkins, M. N., and T. W. Stone (1982) Iontophoretic investigation of the actions of convulsant kynurenines and their interaction with the endogenous excitant quinolinic acid. Brain Res. 247: 184-187.

Perret, C. (1983) Centrally generated pattern of motoneuron activity 
during locomotion in the cat. In Neural Origin of Rhythmic Movements, A. Roberts and B. L. Roberts, eds., pp. 405-422, Cambridge U.P., London, U.K.

Poon, M. L. T. (1980) Induction of swimming in lamprey by L-DOPA and amino acids. J. Comp. Physiol. 136: 337-344.

Roberts, A., and B. L. Roberts, eds. (1983) Neural Origin of Rhythmic Movements (Symposium 37 of the Society for Experimental Biology), Cambridge U.P., London, U.K.

Roberts, A., N. Dale, and S. R. Soffe (1984) Sustained responses to brief stimuli: Swimming in Xenopus embryos. J. Exp. Biol. 112:321336.

Roberts, A., S. R. Soffe, and N. Dale (1986) Spinal interneurones and swimming in frog embryos. In Neurobiology of Vertebrate Locomotion, S. Grillner, P. S. G. Stein, D. Stuart, H. Forssberg, and R. Herman, eds., pp. 279-306, Macmillan Press, London, U.K.

Rovainen, C. M. (1974) Synaptic interactions of identified nerve cells in the spinal cord of the sea lamprey. J. Comp. Neurol. 154: 189206.

Rovainen, C. M. (1985) Effects of groups of propriospinal interneurons on fictive swimming in the isolated spinal cord of the lamprey. J. Neurophysiol. 54: 959-977.

Rovainen, C. M. (1986) The contribution of multisegmental interneurones to the longitudinal coordination of fictive swimming in the lamprey. In Neurobiology of Vertebrate Locomotion, S. Grillner, P. S. G. Stein, D. Stuart, H. Forssberg, and R. Herman, eds., pp. 353370, Macmillan Press, London, U.K.
Russell, D. F., and P. Wallén (1983) On the control of myotomal motoneurones during "fictive swimming" in the lamprey spinal cord in vitro. Acta Physiol. Scand. 117: 161-170.

Sigvardt, K. A., S. Grillner, P. Wallén, and P. A. M. van Dongen (1985) Activation of NMDA receptors elicits fictive locomotion and bistable membrane properties in the lamprey spinal cord. Brain Res. 336 : 390-395.

Soffe, S. R., and A. Roberts (1982) Tonic and phasic synaptic input to spinal cord motoneurones during fictive locomotion in frog embryos. J. Neurophysiol. 48: 1279-1288.

Wallén, P., and S. Grillner (1985) The effect of current passage on NMDA-induced, TTX-resistant membrane potential oscillations in lamprey neurones active during locomotion. Neurosci. Lett. 56: 8793.

Wallèn, P., and T. I. Williams (1984) Fictive locomotion in the lamprey spinal cord in vitro compared with swimming in the intact and spinal animal. J. Physiol. (Lond.) 347: 225-239.

Wallén, P., S. Grillner, J. L. Feldman, and S. Bergelt (1985) Dorsal and ventral myotome motoneurones and their input during fictive locomotion in lamprey. J. Neurosci. 5: 654-661.

Watkins, J. C., and R. H. Evans (1981) Excitatory amino acid transmitters. Annu. Rev. Pharmacol. Toxicol. 21: 165-206.

Watkins, J. C., J. Davies, R. H. Evans, A. A. Francis, and A. W. Jones (1981) Pharmacology of receptors for excitatory amino acids. In Glutamate as a Neurotransmitter, G. Di Chiara and G. L. Gessa, eds., pp. 263-273, Raven Press, New York. 